\title{
Reseñas
}

\section{Norbert Elias and Modern Social Theory}

\author{
DenNis SMith \\ Londres, Sage Publications, 2001
}

Los grandes cara a cara o los grandes frente a Elias. A riesgo de simplificar y como simple punto de partida es eso lo que viene a proponernos Dennos Smith. Sin embargo, y en favor de una ponderación ajustada, no se trataría únicamente de eso. En primer lugar, ese «cara a cara» no es tanto el de la confrontación como el de la comparación, el contraste y la complementariedad. En segundo lugar, ese título de «grandes» podría haber incluido a otros sin menoscabo de los que sí figuran. En torno a sendas puntualizaciones arranca la ponderación a la que me refería.

El objetivo del autor es el abordaje de la cuestión de la modernidad a partir de cinco mapas explicativos diferentes; los confeccionados por Norbert Elias, Hannah Arendt, Talcotte Parsons, Michel Foucault y Zygmunt Bauman. Con todo, no se trataría tan sólo de exponerlos de manera singular sino de confrontar el mapa elaborado por Elias con los del resto de los autores. Como dije, la confrontación ha de entenderse como comparación en consonancia con la hipótesis de trabajo que presenta Smith, a saber: los enfoques de los cinco autores son complementarios entre sí de tal modo que sus fortalezas compensarían cada una de sus debilidades. No es cuestión de decantarse por uno y otro sino de observar el grado de afinidad y diferencia que muestran entre sí en su diagnóstico de la modernidad. Así, lo que se quiere es explorar y yuxtaponer cinco vías explicativas apuntando convergencias y divergencias, acentuando potencialidades $\mathrm{y}$ poniendo de manifiesto debilidades. En función de esto, se opta por una metodología comparativa en la que a lo largo de sucesivos capítulos Elias permanece fijo desfilando ante él, para el análisis, Arendt, Parsons, Foucaul y Bauman.
De este modo queda expuesto el plan general del libro, al hilo del cual surge un primer interrogante: ¿Por qué estos autores frente a Elias y no otros? La razón principal que aduce Smith es que los escritos de todos ellos constituyen una respuesta a la modernidad que tiene presente al menos dos consideraciones comunes: incorporan a sus explicaciones cierta perspectiva procesual y, asimismo, atienden a la tensiones generadas por las fuerzas tendentes tanto al conflicto como al orden social. Junto a esta razón de tipo principal existen otras, si se quiere, relacionadas con vicisitudes personales y biográficas: que Bauman y Foucault conociesen los trabajos de Elias, que Elias atacase sistemáticamente las posiciones teóricas de Parsons y que Parsons hiciese a su vez oídos sordos, que éste último y Arendt fuesen influidos en su juventud por diferentes sucesos vividos en el seno de la universidad alemana o que Elias y Arendt compartiesen orígenes judíos son algunas de las muchas razones que de este orden aporta Smith para justificar la elección de autores. Al cabo, señala, o bien son coetáneos, o bien sólo media entre ellos una única generación.

Por último, la selección, como aclara el autor, responde a su propia intuición; a la intuición de que el diálogo entre todos será fructífero, de lo cual existen evidencias tanto a favor como en contra. En contra, esa animadversión empecinada de Elias hacia los argumentos de Parsons; que Foucault critique duramente a Freud, tan fundamental para Elias; que el propio Bauman cargue contra la teoría eliasiana del proceso civilizatorio o que Elias calificase en su momento a los existencialistas como Heidegger - maestro de Arendt - de locos metafísicos. A favor podría argüirse que tanto Elias como Bauman fueron exiliados judíos en Gran Bretaña, que Foucault 
es un producto de esa Francia tan admirada por Elias, que éste y Parsons publicaron con desigual fortuna en los años treinta o que Elias observase con recelo y temor, al igual que Arendt, al ascenso al poder de Hitler. Si asumimos este abanico de razones y tenemos en cuenta que jamás podrán figurar en estas páginas cuantos se nos ocurran, parece una selección razonable, lo cual no quita para que, según otras afinidades, se hubiera podido considerar la inclusión de autores como Bourdieu, Giddens o, por qué no, Habermas.

Una vez examinados los procedimientos es necesario hablar de los contenidos. El libro se abre con un capítulo introductoria a las aportaciones de Elias, fundamentalmente poniendo el acento en lo relativo a su teoría del proceso civilizatorio. Desde aquí, se accede al núcleo del texto de Smith, esto es, la comparación propiamente dicha entre Elias y cada uno de los autores seleccionados.

El autor abre con Elias y Arendt, quienes difieren en su pronóstico de la modernidad. Mientras que la pensadora, desde una perspectiva que pivota alrededor del mundo clásico, posee una concepción negativa de la misma; Elias, desde su óptica civilizatoria, contempla en ella posibilidades de mejora para el género humano. Las diferencias también afloran cuando Arendt conceptualiza el fenómeno «nazi» en términos de fenómeno prototípico de la modernidad mientras que Elias lo explica como alteración del desarrollo europeo en un sentido decivilizatorio. Las afinidades, por el contrario, se manifiestan cuando se consideran las nociones de «natalidad», en el caso de Arendt, y de «civilidad» en el de Elias. Sendas nociones contemplan la capacidad de acción del individuo en la red de relaciones en la que éste se inserta. De ahí, la insistencia de ambos en la trascendencia de espacios pacificados como marco de tales relaciones - el ágora ateniense o la Corte absolutista - en los que son garantías de continuidad se desarrollan tanto el discurso como la acción. Nuevas convergencias asoman en su explicación del ascenso del totalitarismo - la brutalización de la burguesía, la destrucción del Estadonación o los efectos políticos de la expansión étnico-nacional aunque a la hora de la respuesta final Arendt opta por entender dicho ascenso desde un patrón de fortalecimiento de los controles ligados a la intensidad de la centralización e integración políticas mientras que Elias se decanta por el movimiento inverso, es decir, por explicarlos como proceso de debilitamiento de esa misma centralización e integración.

En lo que toca a Elias y Foucault, cabría apuntar que sus programas de investigación resultan coincidentes. Los dos se ocupan de la cambiante estructura de las coacciones sociales que constriñen al individuo; aplican enfoques procesuales y figuracionales, atienden al vínculo entre la gestión del cuerpo y la conceptualización del Yo, indagan históricamente distintas concepciones normativas de la conducta y llegan a emplear como material empírico manuales y obras sobre el gobierno del comportamiento y la emocionalidad. Las discrepancias aparecen cuando se evalúan los resultados que arroja la modernidad. Para Elias, el avance de la racionalidad hace posible una existencia razonable para los seres humanos; el heterocontrol sobre el comportamiento y los afectos queda atrás conforme discurre el proceso civilitatorio y se afianza un autocontrol que para Foucault no deja de ser heterodeterminación camuflada, sofisticada y en versión contemporánea. El autocontrol eliasiano es en Foucault un cercenador de la espontaneidad interesado como está en el caos y el desorden como caldo de cultivo de tendencias y fuerzas creativas.

El capítulo dedicado a Parsons sería, a priori, el que más problemas presentaría. Al propio Elias, podemos imaginar, le chirriaría que alguien supiese afinidades entre sus postulados y los del sociólogo estadounidense. Smith se empeña en la tarea y termina por encontrarlas proclamando una hipotética complementariedad entre los trabajos de ambos autores. Esa complementariedad residiría en el carácter inintencional y no planeado que Parsons reconoce en la conformación de una Teoría de la Acción y Elias en el proceso de la civilización. Emplearían los dos un enfoque procesual en sus respectivas áreas para dar cuenta de cómo se ha construido la disposición a que el individuo planifique racionalmente sus acciones. Sus análisis serían pues, más compatibles de los que inicialmente sospechó Elias, interconectándose los dos subprocesos de los que respectivamente se ocuparon: Elias de ese subproceso de constitución no planeada de un hábito civilizado que incluye elementos destacados como la racionalización y el cálculo y Parsons del subproceso centrado en la producción de discursos acerca de las formas de acción que a su vez también incluye como 
componentes destacados la racionalización y el cálculo. Es este capítulo el de más difícil resolución de todo el libro. No olvidemos, por ejemplo, que toda la introducción del El proceso de la Civilización la construye Elias como una suerte de contestación al paradigma funcionalista encarnado en Parsons por lo que costaría concebir algún tipo de cercanía entre ambos autores. Sin embargo, de Elias, tan reacio siempre a desvelar sus fuentes intelectuales y proclive a exagerar a la originalidad de sus aportaciones, podría afirmarse que construyó una sociología sobre la que pesa la figura de Parsons como contramodelo que discutir. En cualquier caso, leyendo a Elias se pensaría que nada tiene que ver el sociólogo norteamericano. Smith, arriesgado y perpetrado de paciencia y detenimiento, apunta similitudes que merecerían ulteriores profundizaciones.

Por último, Bauman y Elias, en un capítulo que deja sorprendentemente de lado una las objeciones de mayor calado que se han realizado a la teoría del proceso civilizatorio, obra del propio Bauman en su Modernidad y Holocausto. Bauman ha discutido con consistencia dicha teoría, sobre todo en lo que se refiere al autocontrol y la pacificación social, pero Smith apenas se detienen esta cuestión. Prefiere ilustrar las divergencias entre ambos autores a partir de, por ejemplo, las diferentes concepciones que manejan de la socialización, Elias como elemento básico de la figuración en la que uno se integra; elemento no esencialmente coactivo y Bauman como reglas de conducta impuestas por élites, burócratas, expertos o cortesanos. En relación con esto último, Bauman resta trascendencia a la sociedad cortesana como enclave crucial para el proceso civilizatorio viendo en ella un marco de proselitismo intelectual empleado por muchos para eliminar los vestigios de la cultura tradicional.

He aquí el grueso e la propuesta de Smith, una propuesta que calificaría de inicial por cuanto nos provee de una serie de pautas para recorrer la modernidad según diagnósticos diferentes de a su vez diferentes autores. $Y$ es inicial porque en ningún caso se quiere más que apuntar vías de comparación a la espera de posteriores análisis que resulten exhaustivos y concluyentes. De este modo, el autor plantea distintas posibilidades de contraste que precisarían de desarrollos ampliados en el supuesto de que nos aventurásemos a seguir la senda por él abierta. Se trata de una guía a la que acogerse para caminar por el pensamiento de los cinco autores, siempre tan solicitados por cuantos se plantean la reflexión en torno a las dimensiones de la modernidad y acerca de la sociedad en general. Smith, con su metodología comparativa, escapa al hábito tan común de interpretar a cada autor en su propia clave, esto es, hacer de Foucault una interpretación meramente foucaltiana o de Arendt una arendtiana, por ejemplo. Abrir el abanico de la interpretación en la teoría social mediante el contraste permite que la aproximación a cada enfoque no sea cerrada ni quede predeterminada. Como apunta Smith, hay que rescatar a los autores de sus propios seguidores y confrontarlos entre sí para no caer en visiones prototípicas, manidas o archiconocidas.

Valoración aparte merece la figura de Norbert Elias. Solamente al final de su carrera comenzó a reconocerse el mérito y la valía de sus aportaciones para a partir de ahí efectuar una recepción activa de las mismas. Colocar, como coloca Smith a Elias en un primer plano, conlleva una apuesta por un autor que no se queda atrás en el diálogo con los «grandes». No se trata de hacerlo ingresar por decreto en el «panteón de los ilustres de la sociología» sino comprobar que cuanto legó no desmerece frente a otros. No creo que quepan ya muchas dudas sobre Elias como un clásico del pensamiento y la teoría sociales. Quizá lo que haga falta aún es emplear en la práctica sus teorías; ponerlas a prueba empíricamente. $Y$ en este aspecto, más se hace fuera de nuestras fronteras que dentro. Smith muestra cómo Elias puede soportar el envite. Lo deseable a partir de ahora es que continuásemos envidando.

Fernando AMPUDIA DE HARO 